\title{
Studi Kelayakan Modul IPA Tematik Berbasis Kearifan Lokal dengan Tema Mie Habang
}

\author{
Fitria Rizkiana $^{1) * *}$, Yasmine Khairunnisa ${ }^{1)}$, Herlina Apriani ${ }^{1)}$ \\ ${ }^{1)}$ Universitas Islam Kalimantan Muhammad Arsyad Al Banjari, Banjarmasin \\ *yayakhair08@gmail.com
}

Abstrak: Pada pembelajaran IPA tematik, pemilihan tema yang menarik sekaligus berhubungan erat dengan kehidupan dan lingkungan siswa menjadi hal penting, karena memudahkan siswa memahami materi yang sedang dipelajari. Terlebih lagi jika tema yang diusung dalam pembelajaran IPA tersebut merupakan suatu kearifan lokal yang terdapat di wilayah tempat tinggal siswa. Dengan demikian, integrasi kearifan lokal dan konsep sains ke dalam pembelajaran IPA tematik sangat dianjurkan. Penelitian ini bertujuan untuk menguji kelayakan modul IPA tematik bertemakan mie habang. Adapun metode penelitian yang digunakan yaitu research and development $(R \& D)$ model 4D (Define, Design, Develop, and Dissemination), sedangkan uji kelayakannya didasarkan pada penilaian 3 orang validator (2 orang dosen Program Studi Pendidikan Kimia UNISKA yang masing-masing ahli dalam bidang biokimia dan pendidikan biologi, serta 1 orang guru IPA di SMP Negeri Kuala Kapuas) dan 20 orang siswa kelas VIII yang sudah mempelajari materi sistem ekskresi. Berdasarkan hasil penilaian tersebut didapati bahwa validitas modul IPA tematik masuk dalam kategori sangat tinggi pada ke empat aspek yang dinilai (materi tampilan, evaluasi dan rangkuman), dan hampir seluruh siswa memberikan jawaban Ya pada 13 butir pernyataan yang dinilai. Dengan demikian, dapat dinyatakan bahwa modul IPA bertemakan mie habang yang telah dikembangkan sangat layak digunakan oleh guru dan siswa sebagai media utama dalam pembelajaran.

Kata Kunci: tematik, kearifan lokal, mie habang

\section{PENDAHULUAN}

Perkembangan dan kemajuan dalam dunia Pendidikan, khususnya di Indonesia, melaju dengan sangat pesat. Seiring dengan berjalannya waktu, kurikulum Pendidikan di Indonesia berubah mengikuti perkembangan jaman. Di Indonesia, selain karena perubahan struktural kepemimpinan dalam bidang Pendidikan, kebutuhan dalam dunia Pendidikan pun turut menjadi latar belakang perubahan kurikulum ini (Wirianto, 2014). Jika pada kurikulum tingkat satuan pendidikan (KTSP) tahun 2006 tujuan dalam dunia Pendidikan berfokus pada kompetensi siswa, maka pada kurikulum 2013 kebutuhan dalam Pendidikan di Indonesia adalah mempersiapkan siswa agar memiliki life skill dan karakter (Utami, 2019). Dari pedoman kurikulum 2013 inilah pembelajaran IPA ditetapkan sebagai pembelajaran terpadu yang mengintegrasikan konsep biologi, fisika, dan kimia ke dalam kehidupan sehari-hari dengan tujuan agar siswa memiliki kebermaknaan pengalaman dan keutuhan pengetahuan dalam pembelajaran IPA (Prasetyowati, 2014).

Sebenarnya pembelajaran IPA terpadu atau IPA tematik ini telah dilaksanakan sejak lama, tetapi pada prakteknya pembelajaran IPA terpadu masih belum terlaksana dengan baik (Juwita, 2020). Salah satu alasan yang paling mendasar untuk hal ini adalah ketidaksesuaian latar belakang pendidikan guru dengan tugas mengajarnya (Priyatma et al., 2019). Misal, guru kimia hanya terampil mengajarkan materi kimia. Akibatnya guru tidak menguasai keterpaduan antar konsep IPA (fisika, biologi, dan kimia), apalagi menghubungkannya dengan kehidupan sehari-hari (Juwita, 2020). Selain alasan di atas, peneliti meyakini bahwa ada faktor penting lainnya yang juga menjadi penyebab pembelajaran IPA terpadu sulit dilaksanakan. Salah satunya yaitu media pembelajaran.

Yudiyanto et al (2020) menyatakan bahwa media pembelajaran IPA merupakan unsur penting dalam pembelajaran, karena penggunaannya dapat memotivasi dan membantu siswa memahami materi pelajaran. Guna menunjang pembelajaran IPA terpadu, pemerintah telah menyediakan buku ajar IPA tematik sebagai salah 
satu bentuk media belajar yang dapat digunakan siswa. Hasil telaah peneliti terhadap salah satu buku ajar IPA tematik yang ditulis oleh Zubaidah et al (2017), dapat diketahui bahwa keterpaduan antar konsep kimia, biologi, dan fisika dalam buku tersebut dideskripsikan dengan cukup jelas melalui pemetaan kompetensi dasar dan materi. Namun, peneliti tidak menemukan isu/khas daerah tertentu yang diusung sebagai tema dalam buku tersebut. Padahal, akan lebih baik jika dalam penyampaiannya diselipkan berbagai aspek kearifan lokal yang menjadi ciri khas kedaerahan mencakup ekonomi, budaya, teknologi informasi, komunikasi, ekologi dan lain sebagainya. Pernyataan ini didukung oleh Dewi et al (2014) yang menerangkan bahwa kebermaknaan pembelajaran siswa akan lebih optimal dengan adanya penerapan nilai-nilai budaya lokal dalam pembelajaran. Rahmatih et al (2020) juga menyatakan bahwa penerapan nilai kearifan lokal dapat meningkatkan kemampuan literasi peserta didik dalam pembelajaran IPA. Hal inilah yang melatarbelakangi peneliti untuk membuat modul pembelajaran IPA tematik yang menghadirkan unsur kearifan lokal di dalamnya, agar siswa lebih mudah memahami konsep sains yang disampaikan dan menerapkannya dalam kehidupan sehari-hari. Kearifan lokal yang menjadi tema dalam penelitian ini adalah mie habang sebagai salah satu makanan khas Kalimantan Selatan.

Mie habang adalah salah satu kuliner khas dan favorit warga Kalimantan Selatan. Mie habang biasanya dijual di pagi hari sebagai menu sarapan atau pendamping nasi putih/kuning. Selain itu, ada juga pedagang yang menyajikan mie habang sebagai makanan pendamping bakso. Bahkan, ada beberapa rumah makan di kota banjarmasin yang khusus menyajikan mie habang sebagai menu andalan mereka. Mie habang dalam bahasa Banjar memiliki arti mie merah. Disebut mie merah, karena mienya berwarna merah. Warna merah pada mie ini berasal dari pewarna atau bisa juga berasal dari saus tomat yang dimasukkan dalam proses pembuatannya. Agar daya simpan mie habang relatif lama, biasanya juga ditambahkan bahan pengawet. Berdasarkan penelitian Alawiyah (2019), mie habang yang beredar di pasaran mengandung 1,30\% senyawa boraks dimana kandungan tersebut tidak sesuai dengan peraturan dari BPOM yang melarang penggunaan boraks dalam makanan dan minuman. Kemajuan teknologi dalam bidang pangan terkadang harus dicermati dengan baik. Jangan sampai makanan atau minuman yang kita konsumsi mengandung bahan-bahan kimia berbahaya.

Mie habang dapat dijadikan media dan sumber belajar IPA terpadu untuk siswa SMP. Melalui mie habang, guru dapat mengajarkan tentang sistem ekskresi dalam tubuh serta reaksi kimia yang terlibat; pengaruh mengkonsumsi mie habang yang mengandung pewarna, pengawet, dan pengenyal terhadap kesehatan organ ekskresi; cara mengidentifikasi mie habang yang mengandung formalin dan boraks, serta berbagai materi lainnya. Pemanfaatan mie habang sebagai media dan sumber belajar IPA diharapkan memberi dampak positif bagi siswa. Bukan hanya pada ranah kognitif, tetapi juga pada aspek kehidupan lainnya seperti lebih mengenal, mencintai, melestarikan dan mengembangkan makanan khas tersebut supaya berguna bagi diri sendiri dan keluarga, serta menunjang aspek ekonomi dan pembangunan daerah.

Berdasarkan uraian di atas, maka perlu dilakukan penelitian dan pengembangan modul IPA terpadu tema "Mie Habang" pada materi sistem ekskresi. Adapun tujuan yang ingin dicapai melalui penelitian dan pengembangan tersebut adalah untuk menghasilkan modul IPA terpadu yang valid dan layak digunakan dalam pembelajaran.

\section{METODE}

Penelitian ini menggunakan desain Research and Development (R\&D) yaitu penelitian pengembangan dengan menggunakan metode 4D, yaitu Define, Design, Develop, and Dissemination. Metode ini meliputi tahap menetapkan syarat pembelajaran (define), merancang perangkat pembelajaran (design), menghasilkan produk (develop), dan mengetahui efektivitas produk yang dikembangkan dalam proses pembelajaran (disseminate) (Yanti, Affandi, \& Rosyidah, 2021). Penelitian dilaksanakan di SMP Negeri Kuala Kapuas dengan jumlah sampel 20 peserta didik kelas VIII yang telah mempelajari materi sistem ekskresi. Teknik pengumpulan data yang digunakan untuk mencapai tujuan penelitian ini adalah lembar validasi ahli dan angket respon siswa mengenai kelayakan modul. Semua instrumen ditampilkan dalam bentuk google form untuk memudahkan validator dan peserta didik dalam melengkapi isian instrumen tersebut. Modul IPA tematik sendiri ditampilkan dalam bentuk digital, dimana terdapat materi, gambar, dan juga video dalam modul tersebut untuk menyesuaikan dengan model pembelajaran daring yang saat ini diimplementasikan selama pandemi. Modul IPA dalam bentuk digital seperti ini terbukti dapat meningkatkan kemandirian dan pemahaman peserta didik dalam pembelajaran, khususnya mata pelajaran IPA (Sembiring, Sudatha, \& Simamora, 2021). 


\section{HASIL DAN PEMBAHASAN}

Modul IPA tematik bertemakan mie habang yang digunakan dalam penelitian ini sebagai instrumen dan media pembelajaran yang utama telah divalidasi oleh ahli yang terdiri dari 2 (dua) orang dosen Program Studi Pendidikan Kimia UNISKA dengan spesifikasi bidang ilmu biokimia dan pendidikan biologi serta 1 (satu) orang guru IPA SMP Negeri Kuala Kapuas. Aspek yang dinilai oleh validator adalah aspek materi, tampilan, evaluasi, dan rangkuman. Penentuan kategori dari validitas instrumen mengacu pada pengklasifikasian validitas yang dikemukakan oleh Widiyanto (2018). Hasil validasi ahli dapat dilihat pada Tabel 1.

Tabel 1. Hasil uji validasi ahli

\begin{tabular}{ccccc}
\hline No & Aspek yang Diamati & Rata-rata & Persentase & Kategori \\
\hline 1 & Aspek materi & 3,94 & $98,48 \%$ & Sangat tinggi \\
2 & Aspek tampilan & 3,72 & $93,05 \%$ & Sangat tinggi \\
3 & Aspek evaluasi & 4,00 & $100 \%$ & Sangat tinggi \\
4 & Aspek rangkuman & 4,00 & $100 \%$ & Sangat tinggi \\
\hline
\end{tabular}

Dari Tabel 1 dapat kita lihat bahwa pada aspek materi dan tampilan walaupun tidak mendapatkan nilai rata-rata 4,00 atau $100 \%$, tetapi tetap berada pada kategori validitas sangat tinggi. Sementara itu untuk aspek evaluasi dan rangkuman, ahli memberikan nilai sempurna yang mengindikasikan bahwa validitas kedua aspek ini juga sangat tinggi. Kemudian, hasil uji validasi ini juga disertai dengan saran perbaikan dari ahli agar modul sesuai dengan tujuan dan fungsinya. Tabel 2 berikut berisi sejumlah saran ahli untuk perbaikan modul.

Tabel 2. Saran perbaikan dari ahli

\begin{tabular}{|c|c|c|}
\hline No & Aspek yang Diperbaiki & Saran Ahli \\
\hline 1 & Materi & $\begin{array}{l}\text { Berikan keterangan pada petunjuk modul tentang kegiatan mana } \\
\text { saja untuk mencapai KD } 1 \text { dan kegiatan mana saja untuk } \\
\text { mencapai KD } 2 \text {. }\end{array}$ \\
\hline 2 & & $\begin{array}{l}\text { Buatlah penjelasan yang lebih rinci mengenai pengaruh mie } \\
\text { habang terhadap sistem ekskresi agar tampak hubungan antara } \\
\text { materi dengan tema kearifan lokal yang diusung. }\end{array}$ \\
\hline 3 & & $\begin{array}{l}\text { Pisahkan bahan dan alat praktikum pada bagian mari } \\
\text { bereksperimen model penyaringan darah sebagai pembiasaan } \\
\text { praktikum bagi siswa }\end{array}$ \\
\hline 4 & & $\begin{array}{l}\text { Perbaiki kalimat "deskripsikan struktur ginjal" pada soal latihan } \\
\text { ginjal, karena dapat menyebabkan ketidakpahaman bagi siswa } \\
\text { kelas VIII. }\end{array}$ \\
\hline 5 & Tampilan & $\begin{array}{l}\text { Logo pada sampul letaknya dapat dipindahkan ke bagian atas } \\
\text { dekat dengan nama penulis atau jangan terlalu ke bawah. }\end{array}$ \\
\hline 6 & Evaluasi & $\begin{array}{l}\text { Tambahkan kisi-kisi pada soal evaluasi agar memudahkan guru } \\
\text { mengetahui tujuan pembelajaran yang telah tercapai. }\end{array}$ \\
\hline 7 & Rangkuman & $\begin{array}{l}\text { Pada bagian rangkuman perlu ditambahkan upaya/contoh dalam } \\
\text { kehidupan sehari-hari menjaga kesehatan sistem ekskresi sesuai } \\
\text { dengan kompetensi dasar. }\end{array}$ \\
\hline 8 & & $\begin{array}{l}\text { Perbaiki kesalahan penulisan dan urutan istilah pada bagian } \\
\text { glosarium. }\end{array}$ \\
\hline 9 & & $\begin{array}{l}\text { Variasikan warna pada latar, agar siswa lebih tertarik untuk } \\
\text { membaca isi rangkuman. }\end{array}$ \\
\hline
\end{tabular}

Berdasarkan saran ahli di atas, maka modul IPA tematik telah direvisi pada bagian-bagian yang disebutkan agar modul lebih layak untuk digunakan. Dari hasil yang telah dijabarkan pada Tabel 1 dan 2, dapat disimpulkan bahwa modul IPA tematik bertema mie habang masuk dalam kategori validitas sangat tinggi dan sangat layak digunakan dalam penelitian ini. 
Selain dari validasi ahli, kelayakan modul juga dilihat dari angket respon yang diisi oleh siswa. Angket respon tersebut terdiri atas 13 butir pernyataan dengan pilihan jawaban YA dan TIDAK. Hasil analisis terhadap angket respon siswa tersebut diberikan pada Tabel 3.

Tabel 3. Analisis Angket Respon Siswa

\begin{tabular}{|c|c|c|c|}
\hline No & Respon Siswa & Ya (\%) & Tidak (\%) \\
\hline 1 & Desain modul IPA tematik "Mie Habang" yan $2 \mathrm{~g}$ digunakan menarik & 100 & 0 \\
\hline 2 & Penggunaan modul IPA tematik "Mie Habang" sangat mudah & 100 & 0 \\
\hline 3 & $\begin{array}{l}\text { Video percobaan yang ditampilkan pada link dalam modul IPA } \\
\text { tematik "Mie Habang" mendukung saya untuk lebih memahami } \\
\text { materi sistem ekskresi }\end{array}$ & 95 & 5 \\
\hline 4 & $\begin{array}{l}\text { Gambar/animasi yang digunakan dalam modul IPA tematik "Mie } \\
\text { Habang" membantu saya dalam memahami materi sistem ekskresi }\end{array}$ & 100 & 0 \\
\hline 5 & $\begin{array}{l}\text { Dengan adanya modul IPA tematik "Mie Habang" ini saya } \\
\text { termotivasi untuk mempelajari materi sistem ekskresi }\end{array}$ & 100 & 0 \\
\hline 6 & $\begin{array}{l}\text { Penyampaian materi dalam modul IPA tematik "Mie Habang" ini } \\
\text { berkaitan dengan kehidupan sehari-hari }\end{array}$ & 95 & 5 \\
\hline 7 & $\begin{array}{l}\text { Materi yang disajikan dalam modul IPA tematik "Mie Habang" } \\
\text { mudah dipahami }\end{array}$ & 85 & 15 \\
\hline 8 & $\begin{array}{l}\text { Modul IPA tematik "Mie Habang" memuat soal-soal latihan yang } \\
\text { dapat menguji pemahaman saya mengenai sistem ekskresi }\end{array}$ & 100 & 0 \\
\hline 9 & $\begin{array}{l}\text { Penyajian materi dalam modul IPA tematik "Mie Habang" membantu } \\
\text { saya dalam menjawab soal-soal }\end{array}$ & 95 & 5 \\
\hline 10 & $\begin{array}{l}\text { Bentuk, model, dan ukuran huruf yang digunakan sederhana dan } \\
\text { mudah dibaca }\end{array}$ & 95 & 5 \\
\hline 11 & $\begin{array}{l}\text { Susunan atau tata letak objek dalam modul IPA tematik "Mie } \\
\text { Habang" rapi dan menarik }\end{array}$ & 100 & 0 \\
\hline 12 & $\begin{array}{l}\text { Warna yang digunakan dalam modul IPA tematik "Mie Habang" } \\
\text { serasi dan menarik }\end{array}$ & 100 & 0 \\
\hline 13 & $\begin{array}{l}\text { Sampul/cover modul IPA tematik "Mie Habang" menarik minat saya } \\
\text { untuk melihat isi modul }\end{array}$ & 100 & 0 \\
\hline
\end{tabular}

Berdasarkan Tabel 3, notabene siswa menjawab Ya pada semua butir yang dinilai, yang berarti bahwa sebagian besar siswa menganggap modul IPA tematik yang dikembangkan ini layak untuk digunakan. Namun, ada satu orang siswa yang menjawab tidak pada butir 3, 6, 9, dan 10 serta ada 3 orang siswa yang menjawab tidak pada butir 7. Walaupun demikian, secara keseluruhan semua aspek mendapatkan jawaban positif di atas $80 \%$. Ini menunjukkan bahwa modul IPA tematik bertemakan mie habang ini layak digunakan dalam pembelajaran. Beberapa tampilan modul dapat dilihat pada Gambar 1, 2, 3, 4, dan 5, sedangkan modul lengkapnya dapat dilihat melalui link berikut https://read.bookcreator.com/75RGXtIcuUdxdAHWkUmZQKhqEWJ3/2mVe1SnQ9ytAb7gn7pB8g.

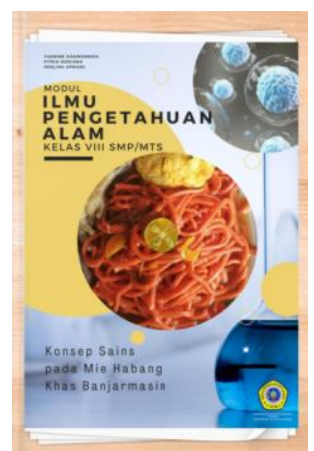

Gambar 1.

Cover buku

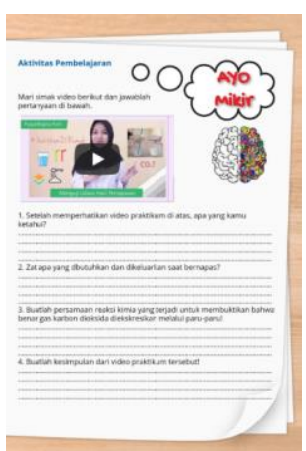

Gambar 2.

Aktivitas

Pembelajaran

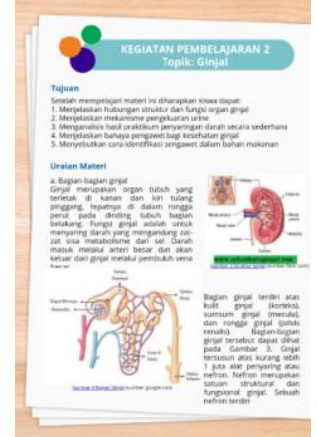

Gambar 3.

Uraian Materi

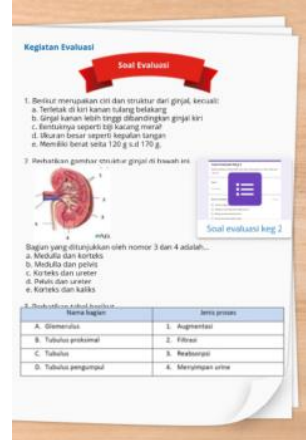

Gambar 4.

Soal Evaluasi

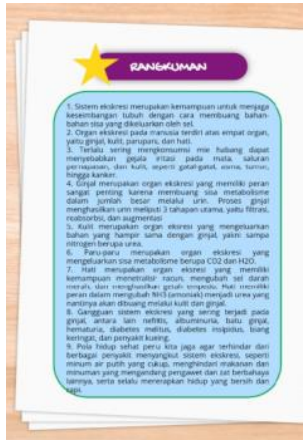

Gambar 5.

Rangkuman 
Hasil penelitian yang menunjukkan bahwa modul IPA tematik yang ditampilkan dalam bentuk digital ini layak digunakan berarti bahwa modul ini dapat digunakan dalam pembelajaran dan penelitian lebih lanjut, terutama untuk mata pelajaran IPA dengan pokok bahasan Sistem Ekskresi. Penelitian oleh Miharja dan Juniawan (2020) juga menggunakan modul tematik dengan kombinasi teks, gambar, dan video untuk pokok bahasan sistem ekskresi dan hasilnya menunjukkan bahwa penggunaan modul tersebut dapat meningkatkan hasil belajar peserta didik. Selain itu, Ahmad dan Iksan (2021) menyatakan bahwa penggunaan modul online dalam pembelajaran IPA sangat tepat untuk melatih penguasaan keterampilan proses sains. Maka dari itu, modul IPA tematik ini perlu untuk diteliti lebih lanjut terkait dengan peningkatan keterampilan peserta didik secara menyeluruh.

\section{SIMPULAN}

Modul elektronik yang telah dikembangkan peneliti mengusung kearifan lokal berupa makanan khas banjar yaitu mie habang. Salah satu materi yang dinilai cocok untuk diintegrasikan dengan kearifan lokal tersebut adalah sistem ekskresi. Pengintegrasian ini bertujuan agar siswa lebih memahami bahwa konsep sains yang mereka pelajari amat dekat dengan kehidupan, sehingga terjadi konstruksi, asimilasi, dan akomodasi konsep di pikiran siswa. Berdasarkan uji validasi ahli terhadap modul IPA tersebut, dapat dikatakan bahwa validitas isi modul masuk dalam kategori sangat tinggi, baik pada aspek penyajian materi, tampilan, evaluasi, ataupun rangkuman. Demikian juga dengan respon siswa, hampir seluruh siswa memberikan jawaban Ya pada 13 butir pernyataan yang dinilai. Dengan demikian, dapat disimpulkan bahwa modul IPA bertemakan mie habang yang telah dikembangkan sangat layak digunakan oleh guru sebagai media utama dalam pembelajaran.

\section{Ucapan Terima Kasih}

Penulis mengucapkan terima kasih kepada semua pihak yang telah membantu terlaksananya penelitian dan penulisan artikel ini, terutama untuk UNISKA MAB Banjarmasin yang telah mendukung secara finansial sehingga penelitian dapat berjalan dengan lancar.

\section{Daftar Pustaka}

Ahmad, N F., Iksan, Z., H. (2021). Edmodo-Based Science Module Development on Students' Mastery of Science Process Skills: Need Analysis. Creative Education, 12(11), 2609-2623. https://doi.org/10.4236/ce.2021.1211195

Alawiyah, T., Yuwindry, I., Nito, P. J. B. (2019). Analisis Senyawa Boraks yang Terkandung Dalam Mie Merah X. Proceeding of Sari Mulia University, Pharmacy National Seminars.

Dewi, N. W., Kristiantari, B. S., Negara, M. G. R., \& Oka, I. G. A. (2014). Model Tematik Bernuansa Kearifan Lokal Berbantuan Media Animasi Berpengaruh terhadap Hasil Belajar IPA Siswa Kelas III SD Negeri Gugus Kapten Japa. Mimbar PGSD Universitas Ganesha, 2(1). http://dx.doi.org/10.23887/jjpgsd.v2i1.3065

Juwita, R. (2020). Analisis Pelaksanaan Pembelajaran IPA Terpadu dalam Kurikulum 2013 Revisi 2017 di SMP Negeri Bandar Lampung. Skripsi. Universitas Islam Negeri Raden Intan Lampung.

Miharja, J., Juniawan, E. A. (2020). Pengembangan Modul Integrated Multimedia pada Materi Sistem Ekskresi Manusia untuk Meningkatkan Kemampuan Analisis Siswa di SMA. BIOSFER: Jurnal Biologi dan Pendidikan Biologi, 5(2), 1-9. http://dx.doi.org/10.23969/biosfer.v5i2.3334

Prasetyowati, R. (2014). Pembelajaran IPA SMP Menurut Kurikulum 2013. Yogyakarta: Jurusan Fisika FMIPA UNY.

Priyatma, B., Sikumbang, D. \& Marpaung, R.R.T. (2019). Analisis Kendala Pendidik IPA terhadap Pembelajaran IPA Terpadu di SMP Swasta. Jurnal Bioterdidik, 7(5), 44-56.

Rahmatih, A. N., Maulyda, M. A., Syazali, M. (2020). Refleksi Nilai Kearifan Lokal (Local Wisdom) Dalam Pembelajaran Sains Sekolah Dasar: Literature Review. Jurnal Pijar MIPA, 15(2), 151-156. https://doi.org/ 10.29303/jpm.v15i2.1663 
Sembiring, W. S., Sudatha, G. W., Simamora, A. H. (2021). E-Modul IPA Untuk Memfasilitasi Siswa Menengah Atas Belajar Mandiri. Jurnal Teknologi Pendidikan Indonesia, 11(1), 26-39. https://doi.org/10.23887/jurnal_tp.v11i1.635

Utami, R. (2019). Integrasi Kurikulum di Indonesia dalam Menghadapi Era Society 5.0. 4th International Conference on Education, 213-218.

Widiyanto, J. (2018). Evaluasi Pembelajaran. Madiun: UNIPMA Press.

Wirianto, D. (2014). Perspektif Historis Transformasi Kurikulum di Indonesia. Islamic Studies Journal, 2(1), 133147.

Yanti, I., Affandi, L. H., Rosyidah, A. N. K. (2021). Pengembangan Media Permainan Ular Tangga Untuk Meningkatkan Kemampuan Berhitung Siswa Kelas II SDN 12 Taliwang. Jurnal Ilmiah Profesi Pendidikan, 6(3), 509-516. https://doi.org/10.29303/jipp.v6i3.280

Yudiyanto, Y., Hakim, N., Hayati, D. K., \& Carolina, H. S. (2020). Pengembangan Video Pembelajaran IPA Terpadu pada Tema Konservasi Gajah Berkarakter Peduli Lingkungan. Journal of Natural Science and Integration, 3(2), 187-195. http://dx.doi.org/10.24014/jnsi.v3i2.8959

Zubaidah, S. et al. (2017). Buku Guru Ilmu Pengetahuan Alam SMP/MTs Kelas VIII. Jakarta: Kementerian Pendidikan dan Kebudayaan. 